\title{
Role of interlekin-35 as a biomarker in patients with newly diagnosed Hashimoto's thyroiditis
}

\author{
${ }^{1}$ Yilmaz H, ${ }^{2}$ Cakmak M, ${ }^{3}$ Ceydilek B, ${ }^{4}$ Demir C, ${ }^{4}$ Aktas A \\ ${ }^{1}$ Department of Internal Medicine, Dr. A. Y. Ankara Oncology Training and Research Hospital, Ankara, Turkey; \\ ${ }^{2}$ Department of Internal Medicine, Turgut Ozal University, School of Medicine, Ankara, Turkey; ${ }^{3}$ Department of Endo- \\ crinology, Turgut Ozal University, School of Medicine, Ankara, Turkey; ${ }^{4}$ Department of Endocrinology, Dr. A. Y. Ankara \\ Oncology Training and Research Hospital, Ankara, Turkey \\ E-mail:drhakkiyilmaz@yahoo.com
}

Objective. Interleukin-35 (IL-35), an interleukin-12 (IL-12) cytokine family member, is shown to be a potent immunosuppressive and anti-inflammatory cytokine. Inducible regulatory $\mathrm{T}$ cells (Tregs) produce IL-35 that mediates the immune inhibitory function of Tregs. Growing evidence revealed that upregulation of IL-35 expression may play a critical role in the prevention of autoimmune diseases in various experimental autoimmunity models and vice versa. Hashimoto's thyroiditis (HT) is considered to be a Treg cell-related autoimmune disease with loss of self-tolerance.

Methods. One hundred-twenty eight subjects, newly diagnosed hypothyroid HT patients [56 overt (Group 1), 72 subclinical hypothyroid (Group 2)] and 38 healthy controls (Group 3) were enrolled in the study. The levels of serum IL-35 were determined by enzyme-linked immunosorbent assay (ELISA).

Results. Serum IL-35 levels were lower in the HT group when compared with subclinical HT group [304.5 (834.6) pg/ml vs. 636.1 (1542.0) pg/ml, p=0.004] and control cases [304.5 (834.6) $\mathrm{pg} / \mathrm{ml}$ vs. $1064.7(2526.8) \mathrm{pg} / \mathrm{ml}, \mathrm{p}<0.001]$. Serum IL-35 levels were inversely associated with thyroid stimulating hormone (TSH; $r s=-0.396, p<0.001$ ) and anti-thyroid peroxidase antibodies (TPOAb; rs $=-0.571, p<0.001)$ in whole group. Serum IL-35 were negatively associated with TSH $(\mathrm{rs}=-0.264, \mathrm{p}=0.003)$ and TPOAb $(\mathrm{rs}=-0.735, \mathrm{p}<0.001)$ in patients with Hashimoto's thyroiditis (Group $1+$ Group 2).

Conclusion. The results suggest that IL-35 may play a role in the pathogenesis of HT.

Key words: IL-35, Hashimoto’s thyroiditis, hypothyroidism, autoimmunity, inflammation

Hashimoto's thyroiditis (HT) is the most common cause of the hypothyroidism in the iodine-sufficient areas of the world. It is a part of the spectrum of autoimmune thyroid diseases (AITDs), in which the thyroid gland is attacked by a variety of cell- and antibody-mediated immune processes (Jacobson and Tomer 2007; Stathatos and Daniels 2012; Cogni and Chiovato 2013; Caturegli et al. 2014; Effraimidis and Wiersinga 2014). Loss of self-tolerance to thyroid antigens is hallmark of HT (Jacobson and Tomer 2007;
Cogni and Chiovato 2013). HT is characterized by the presence of lymphocytic infiltration in the thyroid, circulating thyroid autoantibodies, and thyroid cell apoptosis leading to follicular destruction rather than thyroid stimulation and thyroid cell hyperplasia (Jacobson and Tomer 2007; Stathatos and Daniels 2012; Cogni and Chiovato 2013; Caturegli et al. 2014; Effraimidis and Wiersinga 2014).

Regulatory T cells (Tregs) are a subset of $\mathrm{CD} 4^{+}$ $\mathrm{T}$ cells that are characterized by expression of the 
transcription factor Foxp3 and high surface expression of CD25 (Fehervari and Sakaguchi 2004; AitOufella et al. 2006). Tregs are responsible for maintenance of the immune tolerance through active immune suppression and regulation of immune response (Shevach 2009; Pellerin et al. 2014). Reduction of the Tregs number is thought to play a role in the initiation and development of autoimmune process in thyroid disorders (Bossowski et al. 2013).

Interleukin-35 (IL-35), an IL-12 cytokine family member, is a crucial mediator which promotes CD4+CD25+ $\mathrm{T}$ cell proliferation, inhibits CD8+ $\mathrm{T}$ cell function, and suppresses full-blown inflammation (Collison and Vignali 2008; Collison et al. 2007; $2009 ; 2010)$. Secretion of IL-35 has only been detected in non-stimulated mouse Tregs (Collison et al. 2007) and stimulated human Tregs (Chaturvedi et al. 2011). IL-35 exerts clear immunosuppressive/anti-inflammatory activities in various autoimmunity models such as experimental colitis (Collison et al. 2007, Wirtz et al. 2011), collagen-induced arthritis (Niedbala et al. 2007), autoimmune encephalomyelitis (Collison et al. 2010), autoimmune diabetes (Bettini et al. 2012), and allergic airway disease (Whitehead et al. 2012). The role of IL-35 in autoimmune hypothyroidism, especially HT, is intriguing topics.

Exact mechanism of HT has remained still obscure. The aim of this study was to explore whether circulating levels of IL-35 is related to HT and any components of HT.

\section{Subjects and Methods}

Subjects. One hundred-twenty-eight newly diagnosed hypothyroid HT patients (56 overt, 72 subclinical hypothyroid) were enrolled in the study. Diagnosis of HT was based on three main findings: the presence of goiter, typical ultrasonography, and presence of serum antibodies against thyroid antigens (mainly to thyroperoxidase and thyroglobulin). Subclinical hypothyroidism was defined as elevated serum concentrations of thyroid stimulating hormone ( $\mathrm{TSH}=4.5-10 \mu \mathrm{IU} / \mathrm{ml}$ ), normal serum concentrations of free thyroxine (FT4) and triiodothyronine (FT3), whereas overt hypothyroidism was defined as low free thyroid hormone levels (FT4 or FT3) and TSH $\geq 4.5 \mu \mathrm{IU} / \mathrm{ml}$. Subjects were excluded if she/he had a history of and current nodular-multinodular goiter, chronic respiratory diseases, smoking, neuromuscular disease, narcolepsy, transient ischemic attack, malignancy, renal dysfunction, chronic heart failure, autoimmune hepatitis, type 1 diabetes (T1DM), multiple sclerosis (MS), rheumatoid arthritis, alcoholic abuse or sedative drug user, current pregnancy, other endocrinological diseases, and recent infection.

The control group comprised of apparently healthy individuals, who were not complaining from any chronic medical diseases with normal clinical examinations, no history of thyroid diseases or any chronic illness may interfere with our results.

Informed consent was obtained in all cases, and the study was approved by the local ethics committee (IRB Number: 9950669/351).

All patients with HT were treated after the first examination with oral levothyroxine. Anthropometric measurements, serum lipid and IL-35 levels, were measured at the time of diagnosis. Measurements of anthropometric parameters were performed for the study subjects before breakfast when wearing light clothing and no shoes. The heights and weights were measured. The body mass index (BMI) was calculated as the weight $/$ height $^{2}\left(\mathrm{~kg} / \mathrm{m}^{2}\right)$.

Biochemical analysis. Venous blood samples were collected from the participants by venipuncture after a $12 \mathrm{~h}$-overnight fasting. Serum total cholesterol (TC), triglyceride, and high-density lipoprotein cholesterol (HDL-C) were measured with Cobas 6000 analyzer series (Roche diagnostics, Mannheim, Germany). Serum low-density lipoprotein cholesterol (LDL-C) was calculated using the Friedewald formula: LDL-C=TC-HDL-C-(triglyceride/5.0). Serum hsCRP was analyzed using the same automated chemistry analyzer, and the reference values applied were 0 to $3.0 \mathrm{mg} / \mathrm{l}$. Serum TSH, FT4, FT3, anti-thyroid peroxidase antibodies (TPOAb) and anti-thyroglobulin antibodies ( $\mathrm{TgAb}$ ) levels were evaluated using Cobas e601 (Roche diagnostics, Mannheim, Germany) with electrochemiluminescence immunoassay (ECLIA) method. Normal ranges in our laboratory are as follows: $\mathrm{TSH}=0.27-4.20 \mu \mathrm{IU} / \mathrm{ml}$, FT4 $=0.93-1.70 \mathrm{ng} / \mathrm{dl}$, FT3=2.0 $-4.40 \mathrm{pg} / \mathrm{ml}$, TPOAb $<35.0 \mathrm{IU} / \mathrm{ml}, \mathrm{TgAb}<115.0 \mathrm{IU} / \mathrm{ml}$.

Enzyme-linked immunoassay (ELISA). Blood samples were centrifuged for $15 \mathrm{~min}$ at $1000 \times$ g and separated sera were stored at $-80^{\circ} \mathrm{C}$. Serum levels of IL-35 were determined using commercially available ELISA kit (Cat. No. CSB-E13126h, Cusabio, INC, Wuhan, P.R. China). The intra- and inter-assay coefficients of variation were $6 \%$ and $8 \%$, respectively. Sensitivity was $15.6 \mathrm{pg} / \mathrm{ml}$. All samples were analyzed in duplicates.

Ultrasound (US) evaluation of thyroid gland was performed with an HD15 PureWave Ultrasound System (Philips Medical Systems, Bothell, WA, USA) with using a $5-\mathrm{cm}, 5-12 \mathrm{MHz}$ linear transducer by two blinded radiologists experienced in thyroid imaging. Images were obtained in the transverse and 
longitudinal planes. Thyroid volume for each lobe was calculated using the mean of the elliptical shape volume formula $(\pi / 6 \times$ length $\times$ width $\times$ depth). The sum of two thyroid lobe volumes gave the total thyroid volume (Collison et al. 2009). Volume of the isthmus was not included in this calculation. Definition of Goiter was based on Gutekunst's criteria. Gutekunst reference values for adults $\left(>18 \mathrm{~cm}^{3}\right.$ in women and $>25 \mathrm{~cm}^{3}$ in men) were used (Gutekunst et al. 1986; Gutekunst and Martin-Teichert 1993). US features of diffuse thyroiditis (DT) were defined using the generally accepted standards of diffuse parenchymal hypoechogenicity or a heterogeneous echogenic pattern of the thyroid gland.

Statistical analysis. The normality of parameters was examined by using Kolmogorov-Smirnov test. Continuous data were expressed as means $\pm S D$, median (range) and the differences were analyzed with one-way analysis of variance (ANOVA, normal distribution) or Kruskal-Wallis test with MannWhitney $U$ test (abnormal distribution or unequal variances). If a significant difference was found after ANOVA among groups, we performed paired comparisons with the Tukey post hoc test. Categorical variables were presented by frequency counts, and the differences were tested using the chi-square test or Fisher exact test. Associations of IL-35 with laboratory markers, clinical evaluations and thyroid volume were analyzed by use of Spearman rank order correlations. IBM SPSS Statistics version 20 was used for the statistical analyses and $\mathrm{p}<0.05$ was considered statistically significant.

Table 1

Baseline clinical and biological characteristics of the participants

\begin{tabular}{|c|c|c|c|c|}
\hline Parameter & $\begin{array}{l}\text { Group 1 } \\
(\mathrm{n}=56)\end{array}$ & $\begin{array}{l}\text { Group 2 } \\
(\mathrm{n}=72)\end{array}$ & $\begin{array}{l}\text { Group 3 } \\
(\mathrm{n}=38)\end{array}$ & p-value \\
\hline Age (years) & $38.5 \pm 7.8$ & $38.2 \pm 9.7$ & $39.0 \pm 10.1$ & 0.397 \\
\hline Gender (M/F; \%) & $7 / 49(14.2 \%)$ & $10 / 62(16.1 \%)$ & $5 / 33(15.1 \%)$ & 0.286 \\
\hline BMI $\left(\mathrm{kg} / \mathrm{m}^{2}\right)$ & $28.7 \pm 3.4$ & $28.0 \pm 4.1$ & $27.5 \pm 3.8$ & 0.451 \\
\hline Smokers (n; \%) & $6(10.7 \%)$ & $7(9.7 \%)$ & $4(10.5 \%)$ & 0.612 \\
\hline SBP (mmHg) & $124 \pm 12$ & $120 \pm 14$ & $123 \pm 13$ & 0.803 \\
\hline DBP (mmHg) & $76 \pm 9$ & $78 \pm 11$ & $74 \pm 8$ & 0.772 \\
\hline TC (mg/dl) & $201 \pm 42$ & $199 \pm 45$ & $196 \pm 40$ & 0.329 \\
\hline TG (mg/dl) & $110 \pm 23$ & $112 \pm 25$ & $108 \pm 26$ & 0.518 \\
\hline LDL-C (mg/dl) & $141 \pm 20$ & $135 \pm 18$ & $134 \pm 19$ & 0.104 \\
\hline HDL-C (mg/dl) & $38.5 \pm 7.2$ & $39.1 \pm 8.3$ & $39.5 \pm 7.6$ & 0.371 \\
\hline TSH $(\mu \mathrm{IU} / \mathrm{ml})$ & $21.5 \pm 21.1^{\mathrm{ab}}$ & $7.65 \pm 1.57^{c}$ & $1.70 \pm 0.67$ & $<0.001$ \\
\hline FT4 (ng/dl) & $0.85 \pm 0.22^{\mathrm{ab}}$ & $1.11 \pm 0.29$ & $1.38 \pm 0.16$ & $<0.001$ \\
\hline FT3 (pg/ml) & $1.86 \pm 0.37^{\mathrm{ab}}$ & $2.89 \pm 0.39$ & $2.91 \pm 0.45$ & 0.031 \\
\hline TPOAb (IU/ml) & $1200.5(1718.0)^{\mathrm{de}}$ & $906.0(1731)^{\mathrm{f}}$ & $13.0(33.0)$ & $<0.001$ \\
\hline $\operatorname{TgAb}(\mathrm{IU} / \mathrm{ml})$ & $780.5(1245)^{\mathrm{de}}$ & $567.6(1141)^{\mathrm{f}}$ & $24.2(25.0)$ & $<0.001$ \\
\hline Thyroid volume (ml) & $34.7 \pm 12.3$ & $33.6 \pm 13.1$ & $16.2 \pm 5.3$ & $<0.001$ \\
\hline IL-35 (pg/ml) & $304.5(834.6)^{\mathrm{gh}}$ & $636.1(1542.0)^{\mathrm{k}}$ & $1064.7(2526.8)$ & $<0.001$ \\
\hline
\end{tabular}

BMI - body mass index; SBP - systolic blood pressure; DBP - diastolic blood pressure; TC - total cholesterol; TG - triglycerides; LDL-C - low-density lipoprotein cholesterol; HDL-C- high-density lipoprotein cholesterol; TSH - thyroid-stimulating hormone; FT4 - free thyroxine; FT3 - free triiodothyronine; TPOAb - anti-thyroid peroxidase antibodies; TgAb - anti-thyroglobulin antibodies. Data represent mean \pm SEM. ${ }^{\mathrm{a}} \mathrm{p}<0.01$ Group 1 vs. Group 2 with post hoc Tukey test; ${ }^{b} \mathrm{p}<0.01$ Group I vs. Group 3 with post hoc Tukey test; ${ }^{\mathrm{c}} \mathrm{p}<0.01$ Group 2 vs. Group 3 with post hoc Tukey test; ${ }^{\mathrm{d}} \mathrm{p}<0.001$ Group 1 vs. Group 2 with Mann-Whitney U test; ${ }^{e} \mathrm{p}<0.001$ Group 1 vs. Group 3 with Mann-Whitney $\mathrm{U}$ test; ${ }^{\mathrm{f}} \mathrm{p}<0.001$ Group 2 vs. Group 3 with Mann-Whitney U test; ${ }^{\mathrm{g}} \mathrm{p}=0.004$ Group 1 vs. Group 2 with MannWhitney U test; ${ }^{\mathrm{h}} \mathrm{p}<0.001$ Group 1 vs. Group 3 with Mann-Whitney U test; ${ }^{\mathrm{k}} \mathrm{p}=0.012$ Group 2 vs. Group 3 with Mann-Whitney U test. 


\section{Results}

The subjects were divided into three groups based on the thyroid hormone profile:

Group $1(n=56)$ comprised of newly diagnosed overt hypothyroidism due to HT;

Group $2(\mathrm{n}=72)$ comprised of newly diagnosed subclinical hypothyroidism due to HT;

Group $3(n=38)$ comprised of healthy euthyroid individuals without past or present thyroid diseases and any disease.

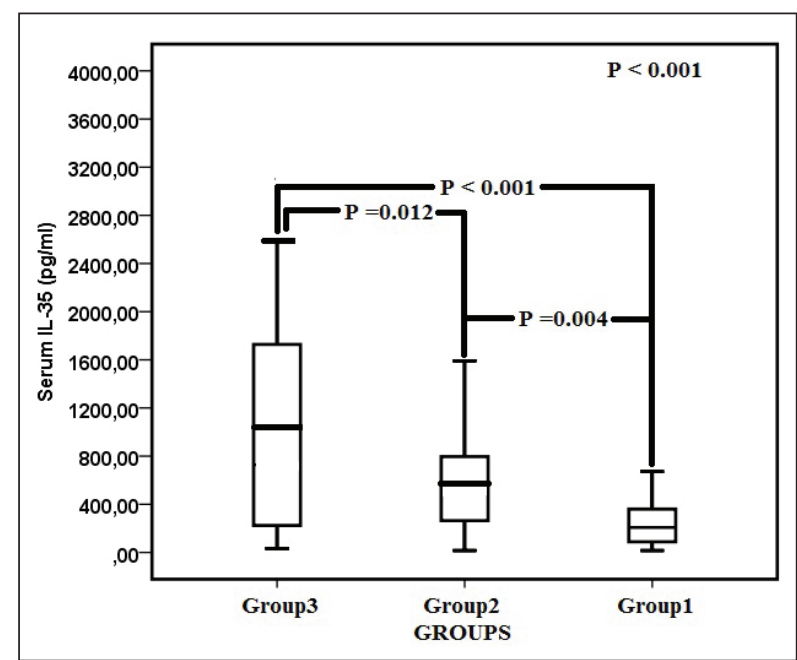

Figure 1. Box-plot shows serum interleukin-35 (IL-35) levels in all groups.

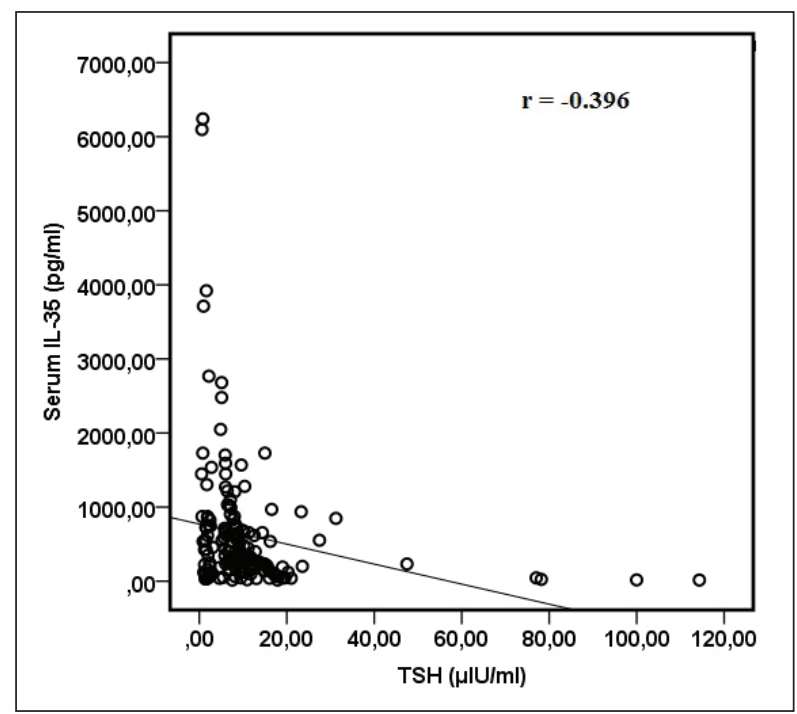

Figure 2. Interleukin-35 (IL-35) levels inversely correlates with thyroid-stimulating hormone (TSH) in all groups.
Characteristics of the groups are shown in Table 1. There was no significant difference among groups in terms of age, gender, smoking, BMI, systolic and diastolic blood pressure values.

The TSH was significantly higher $(\mathrm{p}<0.001)$ in Group 1 compared with Group 2 and Group 3. FT3 and FT4 were significantly lower in Group 1 when compared with Group 2 and Group 3 as shown in Table 1 ( $\mathrm{p}=0.031$ and $\mathrm{p}<0.001$, respectively). On comparison between Group 2 and Group 3, TSH was significantly higher $(\mathrm{p}<0.001)$ in Group 2. FT3 and FT4 were not significantly different between Group 2 and Group 3.

The serum level of IL-35 was significantly lower in the Group 1 than in the Group 2 and Group 3 [304.5 (834.6) vs. $636.1(1542.0)$ vs. $1064.7(2526.8) \mathrm{pg} / \mathrm{ml}$, $\mathrm{p}<0.001]$ (Figure 1). Group 3 had significantly higher levels of serum IL-35 in comparison with Group 2 [1064.7 (2526.8) vs. 636.1 (1542.0), $\mathrm{p}=0.012$ ] (Figure 1).

Correlation analysis revealed that serum levels of IL-35 inversely correlated with TSH ( $\mathrm{rs}=-0.396$, $\mathrm{p}<0.001)$ (Figure 2) and TPOAb ( $\mathrm{rs}=-0.571, \mathrm{p}<0.001)$ (Figure 3) in all groups (Group $1+$ Group $2+$ Group 3). However, there was no significant correlation of IL-35 levels with free thyroid hormones, $\mathrm{TgAb}$, lipid parameters, CRP and thyroid volume $(\mathrm{p}>0.05)$ in all groups. We found that the serum levels of IL35 were negatively correlated with TSH $(\mathrm{rs}=-0.264$, $\mathrm{p}=0.003)$ (Figure 4$)$ and TPOAb $(\mathrm{rs}=-0.735, \mathrm{p}<0.001)$ (Figure 5) in patients with HT (Group $1+$ Group 2). However, no significant correlation was found between IL-35 levels and other parameters (free thyroid hormones, $\mathrm{TgAb}$, lipid parameters, CRP and thyroid volume) ( $p>0.05)$ in patients with HT.

\section{Discussion}

In the present study, serum IL-35 levels were low in patients with newly diagnosed HT. Furthermore, serum IL-35 levels were inversely associated with TSH and TPOAb. To our best knowledge, this is the first study, in which IL-35 levels were evaluated in patients with new-diagnosed HT. IL-35, mainly synthesized by Tregs, has an important role in the pathogenesis of several inflammatory and autoimmune conditions (Collison et al. 2007; Niedbala et al. 2007; Collison et al. 2010, Wirtz et al. 2011; Bettini et al. 2012; Whitehead et al. 2012). IL-35 promotes the immune inhibitory function and proliferation of Tregs. It contributes to development of autoimmune thyroiditis by causing loss of immune tolerance depending on the decrease in number of Tregs and impairment of their function (Shevach 2009; Bossowski et al. 2013; Pel- 


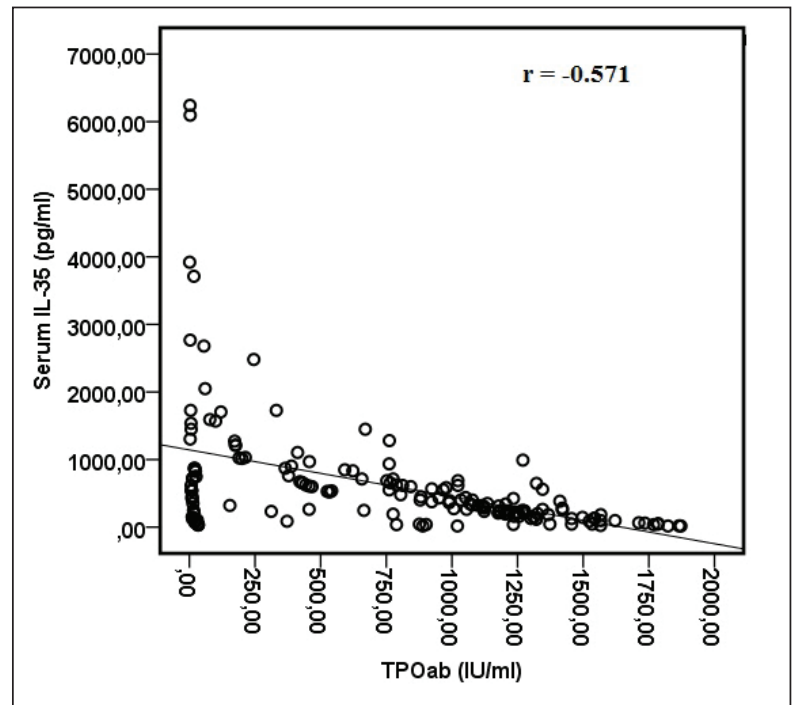

Figure 3. Interleukin-35 (IL-35) levels inversely correlates with anti-thyroid peroxidase antibodies (TPOAb) in all groups.

lerin et al. 2014). In the current study, besides finding low IL-35 levels in the hypothyroidism group, IL-35 levels in the overt hypothyroidism group were found lower than the subclinical group. The relationship between other anti-inflammatory cytokines (IL-4, TGF-beta, IL-10) that have similar properties as IL35 and autoimmune hypothyroidism has been demonstrated. Reduced TGF-beta levels have been associated with HT (Akinci et al. 2008; Vural et al. 2009), whereas increased levels of TGF-beta and IL-10 have been showed to suppress experimental autoimmune thyroiditis (Gangi et al. 2005; Wang et al. 2009; Yu et al. 2010). These studies were consistent with our results, which suggested that decreased levels of IL-35 were related to HT.

The decreased IL-35 levels may contribute to both development of autoimmune thyroiditis and gradual intensification of hypothyroidism by leading to impairment in Treg cell numbers and functions. Besides, IL-35 levels might decrease impairment in Treg cell functions because of impairment in Treg cell functions and decrease in number of Tregs. The most important mechanism that might explain the physiopathological relation between IL-35 and autoimmune hypothyroidism is the reciprocal interactions between IL-35 and Tregs.

The characteristics of thyroid cell destruction for autoimmune thyroiditis can be seen as the consequence of inappropriate expression of Fas or TRAIL death pathway molecules and down-regulation of the apoptosis controlling protein Bcl-2 (Giordano et al. 2001; Stojanovic et al. 2009). Recently, one study

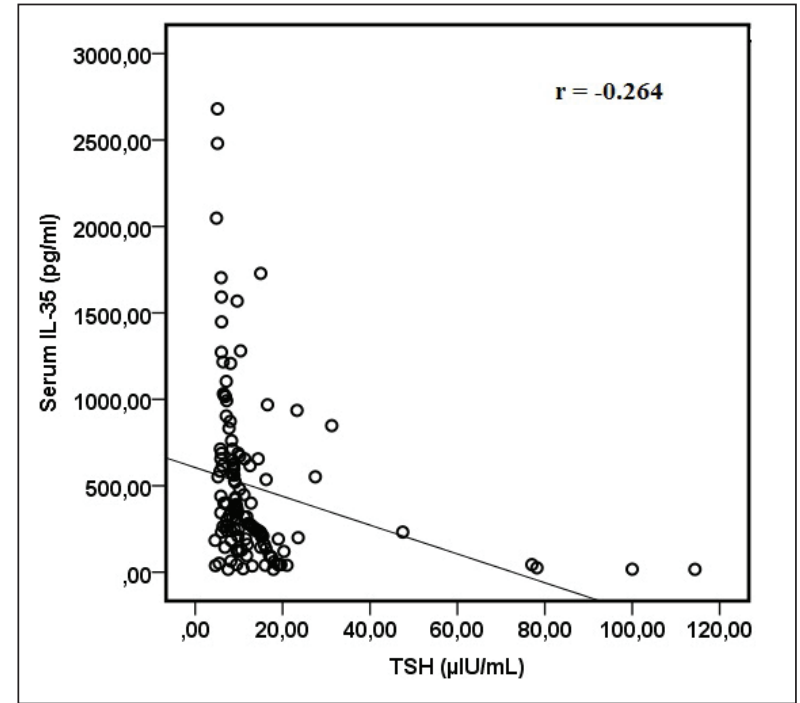

Figure 4. Interleukin-35 (IL-35) levels inversely correlates with thyroid-stimulating hormone (TSH) in Hashimoto's thyroiditis.

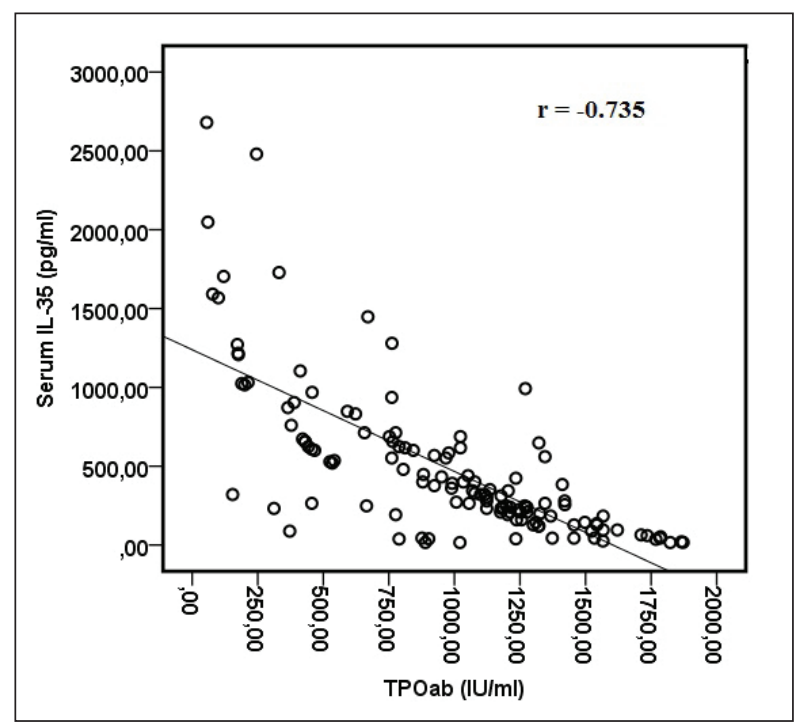

Figure 5. Interleukin-35 (IL-35) levels inversely correlated with anti-thyroid peroxidase antibodies (TPOAb) in Hashimoto's thyroiditis.

has shown that IL-35 inhibited apoptosis in paraffinembedded human pancreas cancer cell lines via an increase in Bcl-2 and a decrease in TRAILR1 (Nicholl et al. 2014). Similarly, we assumed that decreased levels of IL-35 could induce apoptosis that may also be involved in the pathogenesis of HT.

The presence of an inverse relation between IL-35 level and TPOAb is one of the most important findings, which have been demonstrated in the current 
study. Recombinant IL-35 can lead to decreased antibody titers in the mouse model of collagen-induced arthritis (Kochetkova et al. 2010). Decreased levels of IL-35 can mediate the production of antibodies (especially TPOAb) through blocking $\mathrm{T}$ cell regulatory functions (Olson et al. 2013). The results of this study are consistent with our findings. We have demonstrated that as the level of IL-35 increases, TPOAb decreases and as IL-35 level decreases, TPOAb increases. TPOAb and $\mathrm{TgAb}$, polyclonal antibodies of the immunoglobulin $\mathrm{G}$ ( $\mathrm{IgG}$ ) class, are found in high levels in patients with HT (Olson et al. 2013). These antibodies can cause the thyroid destruction by complement activation and antibody dependent cell cytotoxicity, but their role in Hashimoto disease still is unclear (Chardes et al. 2002; Lewis et al. 2013). The increased TPOAb depending on the decrease in IL-35 levels might be one of the mechanisms that contribute to development of HT. Recent study has shown that recombinant IL-35 suppressed the proliferation of primary mouse B cells (Wang et al. 2014). In addition, IL-35 suppressed autoimmune disease via induction of regulatory B cells. We presumed that decreased IL-35 level could lead to stimulate the proliferation of TPOAb-produced B cells.

The present study has several limitations. Firstly, we did not establish causal relationship between IL35 and HT because of cross-sectional design. Secondly, we did not measure the proportion of Tregs in the circulation and thyroid tissue. Thirdly, apoptotic markers (Bcl-2, Fas, TRAIL) were not used to assess the apoptotic activity in the circulation and also thyroid tissue. Fourthly, this study has a relative small sample size.

In conclusion, decreased levels of IL-35 were associated with autoimmune hypothyroidism and its severity. We suggest that IL-35 exerts a protective effect against autodestruction of thyroid tissue. This study was to ascertain whether there could be a role for IL-35 in human autoimmune thyroid disease. We hypothesize that in this condition the role of IL-35 might be directed to the stimulation of Treg cell proliferation and antibody production rather than to the suppression of the inflammation. Further studies are needed to elucidate a link between IL-35 and autoimmune hypothyroidism.

\section{References}

Ait-Oufella H, Salomon BL, Potteaux S, Robertson AK, Gourdy P, Zoll J, Merval R, Esposito B, Cohen JL, Fisson S, Flavell RA, Hansson GK, Klatzmann D, Tedgui A, Mallat Z. Natural regulatory T cells control the development of atherosclerosis in mice. Nat Med 12, 178-180, 2006.

Akinci B, Comlekci A, Yener S, Bayraktar F, Demir T, Ozcan MA, Yuksel F, Yesil S. Hashimoto's thyroiditis, but not treatment of hypothyroidism, is associated with altered TGFbetal levels. Arch Med Res 39, 397-401, 2008.

Bettini M, Castellaw AH, Lennon GP, Burton AR, Vignali DA. Prevention of autoimmune diabetes by ectopic pancreatic $\beta$-cell expression of interleukin-35. Diabetes 61, 1519-1526, 2012.

Bossowski A, Moniuszko M, Dąbrowska M, Sawicka B, Rusak M, Jeznach M, Wojtowicz J, Bodzenta-Lukaszyk A, Bossowska A. Lower proportions of CD4+CD25(high) and CD4+FoxP3, but not CD4+CD25+CD127(low) FoxP3+ T cell levels in children with autoimmune thyroid diseases. Autoimmunity 46, 222-230, 2013.

Caturegli P, De Remigis A, Rose NR. Hashimoto thyroiditis: clinical and diagnostic criteria. Autoimmun Rev 13, 391-397, 2014.

Chardes T, Chapal N, Bresson D, Bes C, Giudicelli V, Lefranc MP, Peraldi-Roux S. The human anti-thyroid peroxidase autoantibody repertoire in Graves' and Hashimoto's autoimmune thyroid diseases. Immunogenetics 54, 141-157, 2002.

Chaturvedi V, Collison LW, Guy CS, Workman CJ, Vignali DA. Cutting edge: Human regulatory T cells require IL35 to mediate suppression and infectious tolerance. J Immunol 186, 6661-6666, 2011.

Cogni G, Chiovato L. An overview of the pathogenesis of thyroid autoimmunity. Hormones (Athens) 12, 19-29, 2013.

Collison LW, Workman CJ, Kuo TT, Boyd K, Wang Y, Vignali KM, Cross R, Sehy D, Blumberg RS, Vignali DA. The inhibitory cytokine IL-35 contributes to regulatory T-cell function. Nature 450, 566-569, 2007.

Collison LW, Vignali DA. Interleukin-35: odd one out or part of the family? Immunol Rev 226, 248-262, 2008.

Collison LW, Pillai MR, Chaturvedi V, Vignali DA. Regulatory T cell suppression is potentiated by target T cells in a cell contact, IL-35- and IL-10-dependent manner. J Immunol 182, 6121-6128, 2009.

Collison LW, Chaturvedi V, Henderson AL, Giacomin PR, Guy C, Bankoti J, Finkelstein D, Forbes K, Workman CJ, Brown SA, Rehg JE, Jones ML, Ni HT, Artis D, Turk MJ, Vignali DA. IL-35-mediated induction of a potent regulatory T cell population. Nat Immunol 11, 1093-1101, 2010. 
Effraimidis G, Wiersinga WM. Mechanisms in endocrinology: autoimmune thyroid disease: old and new players. Eur J Endocrinol 170, R241-R252, 2014.

Fehervari Z, Sakaguchi S. CD4+ Tregs and immune control. J Clin Invest 114, 1209-1217, 2004.

Gangi E, Vasu C, Cheatem D, Prabhakar BS. IL-10-producing CD4+ CD25 + regulatory T cells play a critical role in granulocyte-macrophage colony-stimulating factor-induced suppression of experimental autoimmune thyroiditis. J Immunol 174, 7006-7013, 2005.

Giordano C, Richiusa P, Bagnasco M, Pizzolanti G, Di Blasi F, Sbriglia MS, Mattina A, Pesce G, Montagna P, Capone F, Misiano G, Scorsone A, Pugliese A, Galluzzo A. Differential regulation of Fas-mediated apoptosis in both thyrocyte and lymphocyte cellular compartments correlates with opposite phenotypic manifestations of autoimmune thyroid disease. Thyroid 11, 233-244, 2001.

Gutekunst R, Smolarek H, Hasenpusch U, et al. Goiter epidemiology: thyroid volume, iodine excretion, thyroglobulin and thyrotropin in Germany and Sweden. Acta Endocrinol (Copenh) 112, 494-501, 1986.

Gutekunst R, Martin-Teichert H. Requirements for goiter surveys and the determination of thyroid size. In: Iodine Deficiency in Europe. A Continuing Concern. Delange F, Dunn JT, Glinoer D. Eds. New York: Plenum Press 1993, 109-118.

Jacobson EM, Tomer Y. The genetic basis of thyroid autoimmunity. Thyroid 17, 949-961, 2007.

Kochetkova I, Golden S, Holderness K, Callis G, Pascual DW. IL-35 stimulation of CD39+ regulatory T cells confers protection against collagen II-induced arthritis via the production of IL-10. J Immunol 184, 7144-7153, 2010.

Lewis E, Braverman RD. Werner \& Ingbar's the thyroid: a fundamental and clinical text (10th ed.). Philadelphia: Lippincott Williams \& Wilkins. Chapter 4B, Kopp P 48-74, 2013.

Nicholl MB, Ledgewood CL, Chen X, Bai Q, Qin C, Cook KM, Herrick EJ, Diaz-Arias A, Moore BJ, Fang Y. IL-35 promotes pancreas cancer growth through enhancement of proliferation and inhibition of apoptosis: evidence for a role as an autocrine growth factor. Cytokine 70, 126-133, 2014.

Niedbala W, Wei XQ, Cai B, Hueber AJ, Leung BP, McInnes IB, Liew FY. IL-35 is a novel cytokine with therapeutic effects against collagen-induced arthritis through the expansion of regulatory $\mathrm{T}$ cells and suppression of Th17 cells. Eur J Immunol 37, 3021-3029, 2007.

Olson BM, Sullivan JA, Burlingham WJ. Interleukin 35: key mediator of suppression and the propagation of infectious tolerance. Front Immunol 4, 315, 2013.

Pellerin L, Jenks JA, Begin P, Bacchetta R, Nadeau KC. Regulatory T cells and their roles in immune dysregulation and allergy. Immunol Res 58, 358-368, 2014.

Shevach EM. Mechanisms of foxp3 + T regulatory cell mediated suppression. Immunity 30, 636-645, 2009.

Stathatos N, Daniels GH. Autoimmune thyroid disease. Curr Opin Rheumatol 24, 70-75, 2012.

Stojanovic J, Srefanovic D, Vulovic D, Puskas L, Markovic L. Role of apoptosis in pathogenesis of thyroiditis. Med Pregl 62, 49-52, 2009.

Vural P, Degirmencioglu S, Erden S, Gelincik A. The relationship between transforming growth factor-beta1, vascular endothelial growth factor, nitric oxide and Hashimoto's thyroiditis. Int Immunopharmacol 9, 212-215, 2009.

Wang SH, Chen GH, Fan Y, Van Antwerp M, Baker JR Jr. Tumor necrosis factor-related apoptosis-inducing ligand inhibits experimental autoimmune thyroiditis by the expansion of CD4 + CD25 + regulatory T cells. Endocrinology 150, 2000-2007, 2009.

Wang RX, Yu CR, Dambuza IM, Mahdi RM, Dolinska MB, Sergeev YV, Wingfield PT, Kim SH, Egwuagu CE. Interleukin-35 induces regulatory B cells that suppress autoimmune disease. Nat Med 20, 633-641, 2014.

Whitehead GS, Wilson RH, Nakano K, Burch LH, Nakano H, Cook DN. IL-35 production by inducible costimulator (ICOS)-positive regulatory T cells reverses established IL-17-dependent allergic airways disease. J Allergy Clin Immunol 129, 207-215.e1-5, 2012.

Wirtz S, Billmeier U, McHedlidze T, Blumberg RS, Neurath MF. Interleukin-35 Mediates Mucosal Immune Responses that Protect Against T Cell-Dependent Colitis. Gastroenterology 141, 1875-1886, 2011.

Yu S, Fang Y, Sharp GC, Braley-Mullen H. Transgenic expression of TGF-beta on thyrocytes inhibits development of spontaneous autoimmune thyroiditis and increases regulatory T cells in thyroids of NOD.H-2h4 mice. J Immunol 184, 5352-5359, 2010. 